\title{
A Brief Study of Hybrid Masonry Structural Frame
}

\author{
Ridwan Mohammed Nur \\ Student, Department of Civil \\ Engineering, Ahsanullah \\ University of Science and \\ Technology, Dhaka-1208, \\ Bangladesh
}

\author{
Anjon kumar Das \\ Student, Department of Civil \\ Engineering, Ahsanullah \\ University of Science and \\ Technology, Dhaka-1208, \\ Bangladesh
}

\author{
Kazi Md. Sharif Uddin, \\ Students, Department of Civil \\ Engineering, Ahsanullah \\ University of Science and \\ Technology, Dhaka-1208, \\ Bangladesh
}

\begin{abstract}
In Bangladesh many buildings are found which are not so strong to resist lateral forces such as seismic and wind forces. This research work has been performed to investigate the way of improving the lateral load resisting capacity of buildings. The deflection of different case of structure such as a) Concrete Frame, b) Steel Frame c) Hybrid Masonry Frame system has been investigated in this research work by using civil engineering based finite element analysis software STAAD Pro.-2006.
\end{abstract}

Four (4) sides of a 15 story commercial building has been considered in this research work. The four sides of the frames are the front side frame, back side frame, left side frame, and right side frame respectively.

For Front side frame, the highest value is 11.858 " for concrete frame and the lowest deflection value is 4.241 " for the hybrid masonry frame. Therefore, deflection of the hybrid masonry frame is reduced by $73.66 \%$ with respect to concrete frame structure.

For Back side frame, the highest value is 11.455 " for concrete frame and the lowest deflection value is 4.129 " for hybrid masonry frame. Therefore, deflection of hybrid masonry frame is reduced by $73.50 \%$ with respect to concrete frame structure.

For Left side frame, the highest value is 11.863 " for concrete frame and the lowest deflection value is 3.101 " for the hybrid masonry frame. Therefore, deflection of the hybrid masonry frame is reduced by $79.30 \%$ with respect to concrete frame structure.

For Right side frame, the highest value is 11.455 " for concrete frame and the lowest deflection value is 2.993 " for the hybrid masonry frame. Therefore, deflection of the hybrid masonry frame is reduced by $79.28 \%$ with respect to concrete frame structure.

\section{Keywords}

Hybrid masonry, concrete, steel, deflection, frame, STAAD Pro., finite element analysis, civil engineering.

\section{INTRODUCTION}

Hybrid masonry is a structural system that utilizes reinforced masonry infill walls with a framed structure. While the frame can be constructed of reinforced concrete or structural steel and the masonry can be concrete masonry units or structural clay brick units, the discussion here will include steel frames in combination with reinforced concrete masonry walls [1]. The masonry walls are used as part of the lateral load resisting system.
Load-bearing masonry as a structural system is often in competition with frames of structural steel or concrete as the primary structural system for a building. The interaction of masonry with a frame often leads to construction interferences, particularly with diagonal bracing in building frames. Masonry can be used in combination with steel- or concrete-framed construction to create an efficient hybrid structure that uses the specific qualities of each structural material [2]. Hybrid masonry offers many benefits and complements framed construction. By using the masonry as a structural element for in-plane loads, the constructible of the masonry with the frames is improved, the lateral stiffness are increased, the redundancy is improved, and opportunities for reduced construction costs are created [3].

\section{OBJECTIVE OF THE WORK}

The objectives of the study are as follows:

- To find the vertical load and lateral load shearing aspects of the hybrid steel and masonry.

- To find the greater stiffness with the hybrid masonry system in comparisons with braced frame or moment frames.

- Comparisons lateral deflection between RCC, steel structure and steel structure with hybrid masonry wall.

\section{BACKGROUND}

Masonry has been used as structure since man began building structure. Over time, new uses have been developed for masonry that includes performing as backup, infill, or fireproofing. It has been used as infill for other structural systems for decades.

Since the 1950s, architects and engineers have primarily used cavity walls with framed structures. The backup masonry walls are generally termed infill walls. They support out-ofplane loads on the wall and are isolated from the frame so as not to participate in the lateral load resistance. Codes usually require that these walls be isolated from the lateral movement of the frame so no lateral loads are imparted to the masonry. The hybrid system is a variation of the confined masonry system. It incorporates the beneficial qualities of transitional buildings and the characteristics of the cavity wall construction. It differs from cavity wall construction in that the infill masonry walls participate with the frame and provide strength and stiffness to the system. The masonry can be used as single Wythe or cavity wall construction. Hybrid masonry structures are constructed of reinforced masonry, not unreinforced masonry, as was common in transitional buildings. Hybrid masonry/framed structures were first proposed in print in 2006[1] .There are several primary 
reasons for its development. One reason is to simplify the construction of framed buildings with masonry infill.

While many designers prefer masonry infill walls as the backup for veneers in framed buildings, there is often a conflict created when steel bracing is required and positioned such that conflicts arise with the location of the masonry infill. This leads to detailing difficulties and construction interferences in trying to fit the masonry around braces. One solution is to eliminate the steel bracing and use reinforced masonry infill as shear wall and bracing [2]. Hybrid masonry/steel structures also provide structural redundancy that can be utilized to limit progressive collapse. The reinforced masonry infill results in an alternative load path for the gravity loads of the frame that provides redundancy. The resulting system is more efficient than either a frame or a bearing wall system alone when subjected to progressive collapse design conditions. If a steel column is damaged in a hybrid structure, gravity loads will transfer to the reinforced masonry [4].

\section{MODELING OF STRUCTURE}

Methodology of deflected shapes and values due to the application of different types of frames are obtained here due to following cases,

\section{a. Concrete Frame \\ b. Steel Frame \\ c. Hybrid Masonry Frame}

A 15 story commercial building is considered here as a standard structure. Dimension of structure $51 \mathrm{ft}$. 2 inch $\times 63 \mathrm{ft}$. 2inch. For concrete frame, sizes of beamsB1 18" X 10" B2 18 " X 12"and columns are C1 20" X 10" C2 20" X 12" C3 24" X 16" respectively. For steel and hybrid masonry frame Column HP14×102, Main beam W24×76, Sec. beam W21X104 and bracing W21 $\times 122$. Floor height of $10 \mathrm{ft}$. using linear elastic analysis with the help of finite element software STAAD Pro. under earthquake loads in the equivalent static analysis.

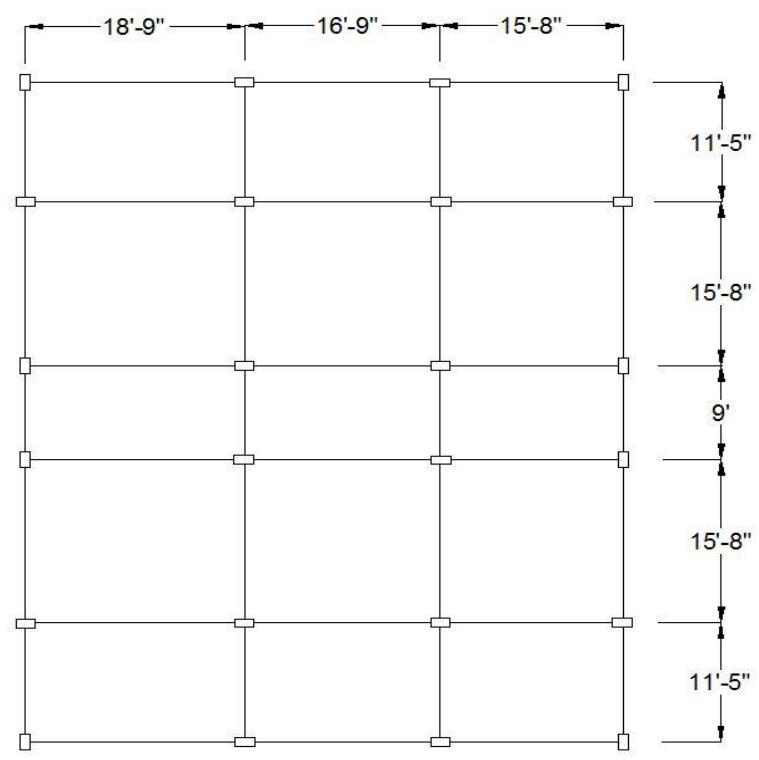

Fig 01: Column layout of the building

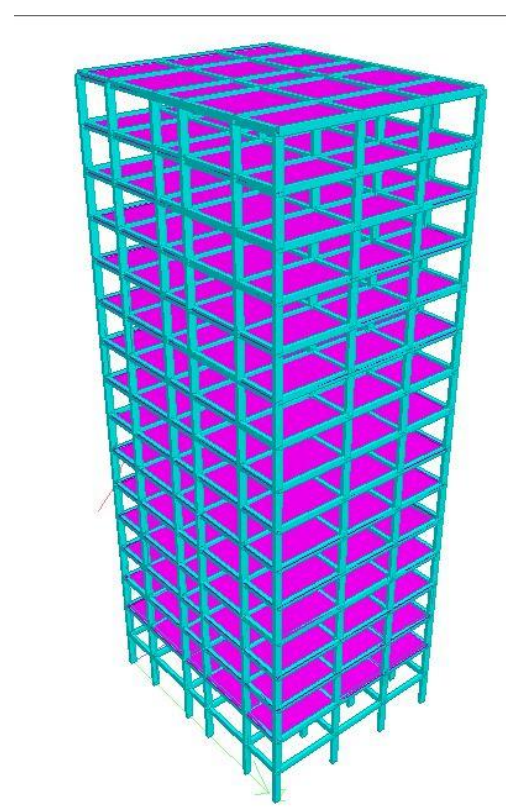

Fig 02: View from STAAD Pro.

Table 01: Node displacement summary of concrete frame

\section{Node Displacement Summary}

\begin{tabular}{|c|c|c|c|c|c|c|c|c|c|}
\hline & die & $\overline{U C}$ & $\begin{array}{l}X \\
\text { (in) }\end{array}$ & $\begin{array}{l}Y \\
\text { (in) }\end{array}$ & $\begin{array}{l}\mathrm{Z} \\
\text { (in) }\end{array}$ & \begin{tabular}{|c|} 
Resultant \\
(in)
\end{tabular} & $\begin{array}{c}\mathrm{rX} \\
\text { (rad) }\end{array}$ & $\begin{array}{l}\mathrm{ry} \\
\text { (rad) }\end{array}$ & $\begin{array}{c}\mathrm{rZ} \\
\text { (rad) }\end{array}$ \\
\hline $\operatorname{Max} X$ & 398 & COMB:DL+1 & 9.413 & -0.507 & -0.001 & 9.427 & 0.000 & -0.000 & -0.002 \\
\hline $\operatorname{Min} X$ & 388 & COMB:DL+L & $-0,492$ & 0.216 & 11.443 & .455 & & 0.00 & .00 \\
\hline $\operatorname{Max} Y$ & 1 & COMB:DL+LI & 0.000 & 0.000 & 0.000 & 0.00 & 0.0 & 0.00 & 0.000 \\
\hline $\operatorname{Min} Y$ & 405 & COMB:DL+Ll & -0.357 & -1.358 & -0.001 & 1.404 & 0.00 & 0.000 & 0.000 \\
\hline $\operatorname{Max} Z$ & 385 & COMB:DL+L & -0.483 & -0.274 & 11.840 & 11.853 & 0.0 & 0.000 & -0.001 \\
\hline $\operatorname{Min} Z$ & 395 & 7:COMB:DL+LI & -0.337 & -0.902 & -0.008 & 0.963 & -0.0 & 0.000 & 0.000 \\
\hline $\operatorname{Max} \Gamma X$ & 122 & 11:COMB:DL+L & -0.135 & -0.177 & 5.273 & 5.278 & 0.0 & 0.000 & 0.000 \\
\hline Min rX & 395 & 7:COMB:DL+LI & -0.337 & -0.902 & -0.008 & 0.963 & -0.0 & 0.000 & 0.000 \\
\hline MaxpY & 345 & 11:COMB:DL+L & 0.017 & -0.665 & 11.031 & 11.051 & 0.0 & 0.001 & 0.000 \\
\hline Min rY & 301 & 10:COMB:DL+1 & 8.400 & -0.411 & -0.000 & 8.410 & -0.0 & -0.001 & -0.003 \\
\hline Max rz & 390 & 7:COMB:DL+LI & -0.368 & -0.871 & 0.001 & 0.945 & -0.000 & -0.000 & 0.001 \\
\hline Min $r z$ & 86 & 10:COMB:DL+1 & 2.327 & -0.139 & 0.000 & 2.332 & 0.000 & -0.000 & -0.007 \\
\hline Max Rst & 401 & 11:COMB:DL+L & -0.405 & -0.931 & 11.825 & 11.868 & 0.002 & 0.001 & 0.000 \\
\hline
\end{tabular}

Table 02: Node displacement summary of steel frame

Node Displacement Summary

\begin{tabular}{|c|c|c|c|c|c|c|c|c|c|}
\hline & Node & $\overline{U C}$ & $\begin{array}{c}x \\
\text { (in) }\end{array}$ & $\begin{array}{c}Y \\
\text { (in) }\end{array}$ & $\begin{array}{l}z \\
\text { (in) }\end{array}$ & $\begin{array}{l}\text { Resultant } \\
\text { (in) }\end{array}$ & $\begin{array}{l}\mathrm{rX} \\
(\mathrm{rg} 0)\end{array}$ & $\begin{array}{l}y \\
(\mathrm{rdd})\end{array}$ & $\begin{array}{l}r z \\
(\mathrm{rd})\end{array}$ \\
\hline $\operatorname{llaxX}$ & 398 & 10:CONB:DL+1 & 4.479 & -0.306 & -0.001 & 4.489 & 0.000 & .0 .000 & -0.001 \\
\hline $\operatorname{lin} X$ & 388 & $11:$ CONBB:DL+L & -0.230 & -0.155 & 5.038 & 5.045 & 0.001 & 0.001 & 0.000 \\
\hline $\operatorname{Max} Y$ & 1 & 7:COMB:DLLLLI & 0.000 & 0.000 & 0.000 & 0.000 & 0.000 & 0.000 & 0.000 \\
\hline $\operatorname{lin} Y$ & 403 & 7COCOB:DL+LL & -0.192 & -0.825 & 0.001 & 0.847 & -0.000 & -0.000 & -0.000 \\
\hline $\operatorname{llax} Z$ & 386 & 11:CONB:DL+L & .0225 & .0279 & 5.446 & 5.458 & 0.002 & .0 .000 & .0 .000 \\
\hline $\operatorname{lin} z$ & 395 & 7:CONB:DLLLLI & -0.170 & -0.567 & -0.008 & 0.592 & -0.001 & 0.000 & -0.000 \\
\hline $\operatorname{Max} I X$ & 146 & 11:CONBB:DL+L & .0 .076 & -0.128 & 2.884 & 2.888 & 0.002 & .0 .000 & 0.000 \\
\hline Min $x$ & 395 & 7COOMB:DLLLLI & -0.170 & -0.567 & -0.008 & 0.592 & -0.001 & 0.000 & -0.000 \\
\hline $\operatorname{Maxpy}$ & 328 & 10:COIIB:DLL+1 & 3.985 & -0.246 & 0.000 & 3.993 & 0.000 & 0.001 & .0 .001 \\
\hline Minny & 325 & 10:CONB:DL+1 & 3.985 & -0.246 & -0.000 & 3.993 & -0.000 & -0.001 & -0.001 \\
\hline $\operatorname{Max} \times 2$ & 390 & 7.COMB:DLLLLI & -0.201 & -0.564 & 0.001 & 0.599 & -0.000 & -0.000 & 0.001 \\
\hline Minnz & 86 & 10:CONB:DL+1 & 1.125 & -0.077 & 0.000 & 1.128 & 0.000 & -0.000 & -0.003 \\
\hline Whax Rst & 403 & 11:COMBB:DL+L & -0.158 & .0 .006 & 5.438 & 5.474 & 0.000 & 0.000 & .0 .000 \\
\hline
\end{tabular}


Table 03: Node displacement summary of hybrid masonry frame

\section{Node Displacement Summary}

\begin{tabular}{|c|c|c|c|c|c|c|c|c|c|}
\hline & Node & $\overline{U C}$ & $\begin{array}{c}x \\
\text { (in) }\end{array}$ & $\begin{array}{l}y \\
\text { (in) }\end{array}$ & $\begin{array}{l}z \\
\text { (in) }\end{array}$ & \begin{tabular}{|c|} 
Resultant \\
(in)
\end{tabular} & $\begin{array}{l}\mathrm{rX} \\
(\mathrm{rad})\end{array}$ & $\begin{array}{l}\text { त" } \\
\text { (rod) }\end{array}$ & $\begin{array}{l}\mathrm{IZ} \\
\text { (ad) }\end{array}$ \\
\hline $\operatorname{Max} X$ & 398 & 10:COMB:DL+1 & 5.219 & .0 .211 & 0.006 & 5.223 & 0.000 & .0 .001 & .0 .002 \\
\hline $\operatorname{lin} X$ & 388 & 11:CONBB:DL+t. & -0.187 & -0.161 & 2.956 & 2.966 & 0.001 & 0.002 & 0.000 \\
\hline $\operatorname{Max} Y$ & 60 & 10:CONB:DL+1 & 0.756 & 0,009 & 0.010 & 0.756 & -0.000 & 0.000 & -0.002 \\
\hline $\operatorname{lin} Y$ & 403 & 7:COMB:DLtLL & -0.170 & 0.811 & 0.001 & 0.829 & -0.000 & -0.000 & -0.000 \\
\hline $\operatorname{Max} Z$ & 386 & 11:CONB:DL+L. & -0.178 & .0 .245 & 3.927 & 3.939 & 0.002 & -0.001 & 0.000 \\
\hline $\operatorname{lin} Z$ & 100 & 10:COMB:DLt+1 & 1.223 & .0 .313 & -0.017 & 1.330 & -0.000 & 0.001 & -0.002 \\
\hline $\operatorname{liax}+x$ & 146 & 11:CONB:DL+L. & -0.067 & -0.113 & 2.157 & 2.161 & 0.002 & -0.001 & 0.000 \\
\hline Min $x$ & 395 & 7.COMB:DLtLL & -0.119 & .0 .553 & -0.008 & 0.565 & -0.001 & 0.000 & 0.000 \\
\hline $\operatorname{Max} \times y$ & 328 & 10:COMB:DL+1 & 4.268 & -0.165 & 0.010 & 4.271 & 0.000 & 0.003 & .0 .002 \\
\hline Minny & 325 & 10:COMB:DL+1 & 4.338 & -0.162 & 0.008 & 4.341 & -0.000 & -0.003 & .0 .002 \\
\hline $\operatorname{lnax} \times 2$ & 390 & 7 COMB:DL+LL & -0.181 & .0 .525 & 0.001 & 0.556 & -0.000 & -0.000 & 0,001 \\
\hline Minnzz & 110 & 10:COMB:DL+1 & 1.763 & -0.061 & 0.007 & 1.764 & 0.000 & -0.000 & -0.003 \\
\hline Whax Rst & 406 & 10:COMB:DL+1 & 5.207 & .0 .614 & -0.002 & 5.243 & 0.000 & .0 .001 & .0 .000 \\
\hline
\end{tabular}

\section{PROBLEM STATEMENT}

To carefully observe the deflection of the building, we categorized the nodes of the building into three parts, these are
a. Concrete Frame
b. Steel Frame
c. Hybrid Masonry Frame

We applied different loads on the nodes of different sections of the building and run our analysis, after completing the analysis we noticed the variety of the deflections at different nodes at different sections.

\section{RESULTS AND DISCUSSION}

Comparisons of the node displacement curve of all frames are obtained here in this research work, three types of frame system have been considered figure 3 shows height vs. deflection curve of front side for all types of the frame system.

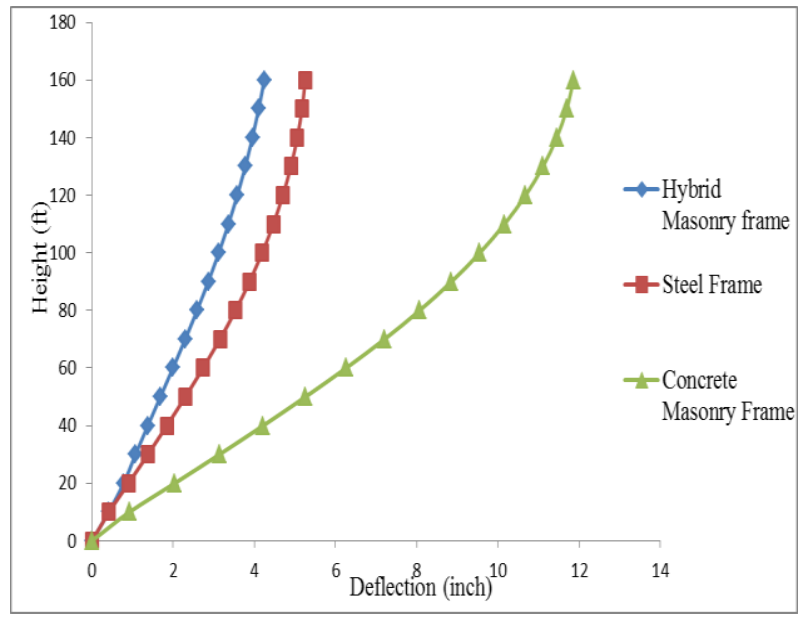

Fig 03: Height vs. Deflection curve of front side of concrete, steel \& hybrid masonry frame
Deflection values of the top nodes in cases of concrete, steel and hybrid masonry frame are 11.858", 5.251", and 4.241" respectively. The highest value is 11.858 " for concrete frame and the lowest deflection value is 4.241 " for the hybrid masonry frame. Therefore, deflection of the hybrid masonry frame is reduced by $73.66 \%$ with respect to concrete frame structure.

Figure 4. shows height vs. deflection curve of back side for all types of the frame system.

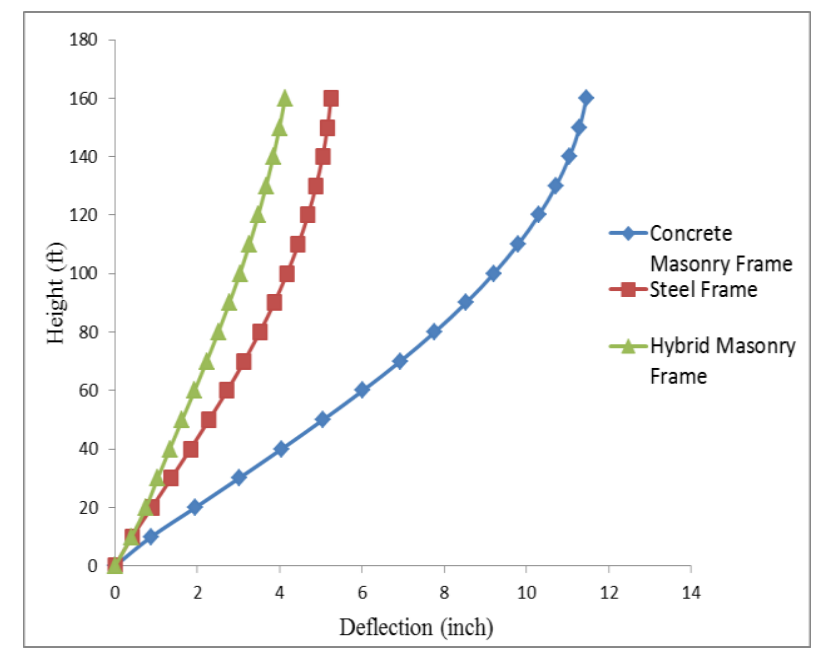

Fig 04: Height vs. Deflection curve of back side of concrete, steel \& hybrid masonry frame

Deflection values of the top nodes in cases of concrete, steel and hybrid masonry frame are 11.455", 5.246", and 4.129" respectively. The highest value is 11.455 " for concrete frame and the lowest deflection value is 4.129 " for the hybrid masonry frame. Therefore, deflection of the hybrid masonry frame is reduced by $73.50 \%$ with respect to concrete frame structure.

Figure 4.27 shows Height vs. Deflection curve of left side of concrete, steel \& hybrid masonry frame

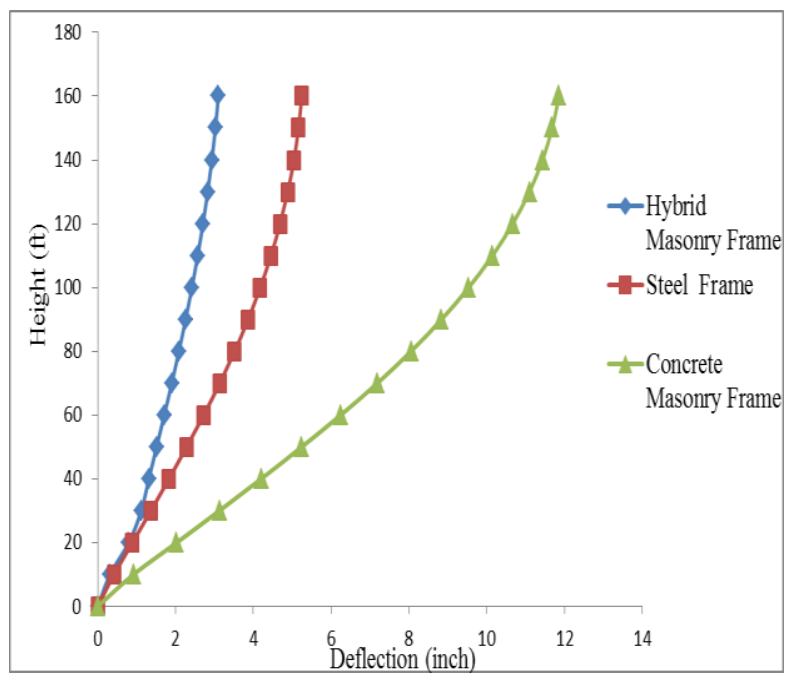

Fig 05: Height vs. Deflection curve of left side of concrete, steel \& hybrid masonry frame 
Deflection values of top nodes in cases of concrete, steel and the hybrid masonry frame are 11.863", 5.246", and 3.101" respectively. The highest value is 11.863 " for concrete frame and the lowest deflection value is 3.101 " for the hybrid masonry frame. Therefore, deflection of the hybrid masonry frame is reduced by $79.30 \%$ with respect to concrete frame structure.

Figure 6 shows height vs. deflection curve of right side for all types of frame system.

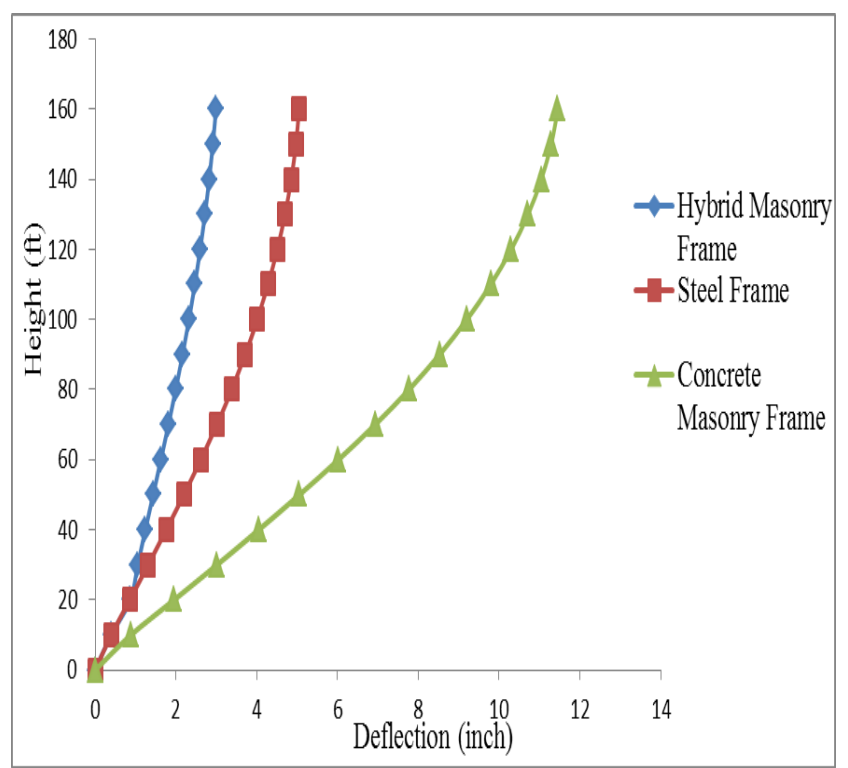

Fig 6: Height vs. Deflection curve of right side of concrete, steel \& hybrid masonry frame

Deflection values of top nodes in cases of concrete, steel and the hybrid masonry frame are 11.455", 5.049", and 2.993" respectively. The highest value is 11.455 " for concrete frame and the lowest deflection value is 2.993 " for the hybrid masonry frame. Therefore, deflection of the hybrid masonry frame is reduced by $79.28 \%$ with respect to concrete frame structure.

\section{CONCLUSIONS}

As steel is not widely popular in Bangladesh as a construction, material so it was not possible to describe all properties based on this country. We tried to describe these as a concept, based on other neighboring and foreign countries. So for further research, suggest to analyzing all properties and designing concepts of steel based on feasibility concern in Bangladesh. Here is the deflection of the hybrid masonry frame is less than the concrete frame structure. Therefore, for compliments frame construction this hybrid masonry frame is more preferable than the others frame. It is also important to increase lateral stiffness of the structure, to improve the redundancy factor, increase frame ability to prevent a possible progressive collapse. Adopting steel frame with hybrid wall could be a transitional step towards modernizations of construction methods in developing countries.

\section{REFERENCES}

[1] Biggs, D.T., Hybrid Masonry Structures, Proceedings of the Tenth North American Masonry Conference The Masonry Society, Boulder, CO, June 2007.

[2] Beall 2003; Beall, C.; "Masonry Design and Detailing, Fifth Edition"McGraw-Hill, 2004

[3] Biggs, D.T., Masonry Aspects of the World Trade Center Disaster, the Masonry Society, Boulder, CO., 2004.

[4] Biggs 2004: Biggs, D.T., "Masonry Aspects of the World Trade Center Disaster", The Masonry Society, Boulder, CO.

[5] Bertero, V.V., and Brokken, S. 1983. Infills in seismicresistant buildings. ASCE Journal of the Structural Division.

[6] Hybrid Concrete Masonry Construction Details,TEK 33B,National Concrete Masonry Association,Herndon,VA,2009

[7] IMI Technology Brief 02.13.02, Hybrid Masonry Construction, International Masonry Institute, Annapolis, MD, 2009

[8] Masonry Advisory Council 2002: "Design Guide for Taller Cavity Walls," Masonry Advisory Council, Park Ridge, IL, 2002

[9] STAAD.Pro 2006, Research Engineers International, a Bentley Solutions Center.

[10] Bangladesh National Building Code (BNBC) 2006. 